\title{
Processes and Pathways: How Do Mathematics and Science Partnerships Measure and Promote Growth in Teacher Content Knowledge?
}

Patricia S. Moyer-Packenham

Utah State University
Arla Westenskow

Utah State University

Intense focus on student achievement results in mathematics and science has brought about claims that K-12 teachers should be better prepared to teach basic concepts in these disciplines. The focus on teachers' mathematics and science content knowledge has been met by efforts to increase teacher knowledge through funded national initiatives focusing on mathematics and science. The purpose of the present study was to look across projects in the National Science Foundation's Math and Science Partnership Program to determine how partnerships developed processes for measuring growth in teacher content knowledge. Pre-and post-testing was the most common process for measuring growth in content knowledge, with 63\% of the mathematics and $78 \%$ of the science teachers showing significant gains in content knowledge. A notable difference was found between teacher outcomes when the Learning Mathematics for Teaching instrument was used in comparison with the use of other instruments measuring teacher content knowledge growth. Results revealed two pathways for promoting teacher content knowledge growth: content explicit, where the goal of growth in teacher content knowledge was explicit in the activity, and content embedded, where the goal of growth in teacher content knowledge was embedded in the activity. As a result of the analysis, a framework demonstrating the interrelationships among processes and pathways was developed. ${ }^{1}$

Intense focus on student achievement results in mathematics and science has brought about claims that K-12 teachers should be better prepared to teach basic concepts in these disciplines. As a result, renewed emphasis has been placed on knowledge development in mathematics and science in both teacher preparation and teacher professional development programs. Prominent among these efforts have been attempts to document the knowledge needed for teaching mathematics and science and efforts to make connections between teacher knowledge and student achievement outcomes (Bolyard \& MoyerPackenham, 2008; Goldhaber \& Brewer, 1997; Hill \& Ball, 2004; Hill, Dean, \& Goffney, 2007; Hill, Rowan, \& Ball, 2005; Moyer-Packenham, Bolyard, Kitsantas, \& Oh, 2008; Rice, 2003).

The focus on teachers' mathematics and science content knowledge has been met by efforts to increase teacher knowledge through funded national initiatives focusing on mathematics and science (see for example, www.ed.gov/ or www.nsf.gov/). One of these efforts, the National Science Foundation's Math and Science Partnership (NSF MSP) Program, has played an important role in funding projects nationwide. To date, a nine-year investment in the NSF MSP Program has placed a consistent emphasis on improving teachers' mathematics and science content knowledge. In 2005, the NSF Committee of Visitors made the following recommendations for the NSF MSP Program: "Processes for measuring growth in teacher content knowledge and effectiveness are less welldeveloped, ... NSF should pay attention to pre- and posttesting of teachers, to classroom observation, and in general to ensuring that across projects the growth of teacher knowledge can be measured" (National Science Foundation, 2005, p. 8).

The purpose of the present study was to look "across projects" in the NSF MSP Program to determine how MSPs measured growth in teacher content knowledge. To address this purpose, the present study focused on the identification of processes for measuring growth used by the MSPs that provide evidence of changes in teachers' mathematics and science content knowledge.

\section{The Importance of Developing Mathematics and Science Teachers' Content Knowledge}

In recent years, publications and position statements produced by professional associations show an unmistakable emphasis on the importance of teachers' mathematics and science content knowledge. The Council of Scientific Society Presidents' (2004) definition of a "well-qualified" mathematics or science teacher focuses on knowing and understanding mathematics and science deeply; the Conference Board of the Mathematical Sciences (2001) published recommendations for the preparation of elementary, middle, and high school teachers of mathematics, emphasizing minimum mathematics coursework preparation standards; and the National Council of Teachers of 
Mathematics and the National Science Teachers Association emphasize the importance of mathematics and science content knowledge expertise (National Council of Teachers of Mathematics, 2005; National Science Teachers Association, 2004). Subject-specific knowledge does matter for teaching at all grade levels, $\mathrm{K}$ through 12 , not just for high school teachers. The recommendations of these professional organizations are founded on numerous studies in mathematics and science that report significant relationships between teachers' subject-specific knowledge and student achievement outcomes (for a review of this literature, see, e.g., Bolyard \& Moyer-Packenham, 2008). There are several large-scale reviews that show subject-specific preparation linked with teacher effectiveness (Darling-Hammond, 2000; Darling-Hammond \& Youngs, 2002; Wilson, Floden, \& Ferrini-Mundy, 2001).

\section{Measuring and Promoting Growth in Teachers' Content Knowledge}

Numerous researchers and psychometricians have focused on designing and validating processes for measuring growth in teachers' content knowledge. In an examination of the first three years of the NSF MSP Program, a review of 282 instruments in use by 48 partnerships indicated that MSPs were using a variety of methods to evaluate their teacher quality goals, including surveys, questionnaires, exams, observations, interviews, portfolios, and archival records (Moyer-Packenham et al., 2008). This previous research was conducted at a time when MSPs were in their first, second, or third year of funding from the NSF. This prior instrument review indicated that $81 \%$ of the MSPs used at least one instrument to measure teachers' content knowledge; $68 \%$ used at least one instrument to measure teachers' mathematics content knowledge; $67 \%$ used at least one instrument to measure teachers' science content knowledge; and 33\% measured mathematical knowledge for teaching (MKT) as defined by Hill and Ball (2004) using some form of the Learning Mathematics for Teaching (LMT) instrument (Hill \& Ball, 2004; Hill et al., 2005).

In addition to developing processes for measuring growth in teachers' mathematics and science content knowledge, partnerships in the NSF MSP Program have made significant efforts to create pathways for promoting knowledge growth. In a review of a cross-sectional sample of 2,340 professional development activities designed and implemented by the MSPs, the most common forms of professional development used as pathways to promote knowledge growth were content-focused courses and workshops (Moyer-Packenham, Bolyard, Oh, \& Cerar,
2010). In a survey of 44,933 public school teachers by the National Center for Education Statistics (NCES, 2005), NCES reported that most forms of professional development continue to be a traditional model of delivery (i.e., courses and workshops) rather than professional development forms that are more reform oriented and embedded in the school culture (i.e., learning communities and study groups). The National Staff Development Council also reported that, while nine out of 10 teachers have participated in professional development in the form of shortterm workshops, fewer teachers have participated in extended learning and more collaborative professional opportunities (Darling-Hammond, Wei, Andree, Richardson, \& Orphanos, 2009).

Pathways for developing teachers' mathematics and science content knowledge are also occurring at the U.S. Department of Education's Mathematics and Science Partnership (ED-MSP) Program (http://www.ed-msp. net/). The ED-MSPs report that summer institutes and in-school follow-up activities are primary methods of teacher professional development to increase mathematics and science content knowledge. They also report additional content development methods for teachers including "mentoring, coaching, lesson study groups, and distance learning" (U.S. Department of Education, 2008, p. 7). The ED-MSP Program shares some similar goals with its NSF counterpart (http://www.nsf.gov/ehr/MSP/). When comparing the two MSP initiatives (ED-MSP and NSF MSP), the overall number of projects funded by the ED-MSP is much larger than those at the NSF (436 projects in fiscal year [FY] 2005 at the ED-MSP compared with 52 projects in FY 2009 at the NSF); however, the projects funded by the ED-MSP serve a smaller number of mathematics and science teachers $(37,355$ teachers served in FY 2005 at the ED-MSP compared with over 141,000 teachers served by the NSF MSP Program) (NSF, 2007; U.S. Department of Education, 2008, p. 15). This report indicated that "More than three quarters of K-5 teachers assessed (76\%) significantly increased their content knowledge as a result of the MSP program" (U.S. Department of Education, 2008, p. 4). The results from previous research on the NSF MSPs and the ED-MSPs show evidence of a variety of methods for measuring and promoting growth in teachers' mathematics and science content knowledge.

The present study sought to answer the following research questions and subquestions: (1) What are the processes for measuring growth in teachers' mathematics and science content knowledge in the NSF MSP Program?: (a) What is the scope of the involvement of K-12 mathematics and science teachers in professional 
development provided by the MSPs?; (b) What gains in mathematics and science teacher content knowledge are reported by the MSPs?; (c) What is the relationship between gains in teacher content knowledge reported by the NSF MSPs and the ED-MSPs?; and (d) What are the most common measures being used to assess gains in teacher content knowledge reported by the NSF MSPs? and (2) How are the pathways, used to promote growth in teachers' mathematics and science content knowledge, related to the processes used for measuring growth in the NSF MSP Program?

\section{Data Sources}

\section{Methods}

The data gathered in this study included primary and secondary source materials and documents obtained from $48^{2}$ funded partnerships in the NSF MSP Program. The 48 funded MSPs included 12 comprehensive (partnerships focused on K-12 mathematics, science, or both), 28 targeted (partnerships focused on a narrower grade range or disciplinary focus in mathematics and/or science), and 8 institute partnerships (focused on developing mathematics and science teachers as school- and district-based intellectual leaders and master teachers).

Data for the analysis were gathered using three primary methods: (a) site visits to each of the MSPs by the MSP Program Evaluation (PE); (b) presentations by the MSPs at an annual partnership conference; and (c) secondary source documents, including self-report surveys, annual reports, and evaluation reports. The list that follows indicates the specific MSP document files analyzed during this study: (a) 47 site visit reports; (b) 46 presentation abstracts from a MSP Learning Conference; (c) four years of data from four surveys compiled in the Compendium of MSP MIS Data for Comprehensive, Targeted, and Institute Projects (Hershey-Arista, Miyaoka, Silverstein, \& Frechtling, 2007); (d) 107 annual reports; and (e) 102 evaluation reports.

\section{Data Collection Procedures}

Site visits. Members of the MSP-PE conducted site visits to the MSPs to interview leaders of the MSPs and review their findings and evaluation data. Evaluators used a protocol to focus data collection on specific topics including teacher quality, quantity, and diversity. A written document, providing a synthesis and analysis of activity at the MSP at the time of the visit, was compiled for the 47 site visits. The collection of these data and the writing of the reports took place over a two-year period.

Presentations. The NSF hosted an annual conference for partnerships in the program where 46 MSPs presented information on their activities and provided written abstracts of their presentations. The written abstracts served as a second source of data on teacher content knowledge development. Researchers in the present study analyzed the notes from evaluators who attended the conference and written abstracts provided by the MSPs for evidence of growth in teacher content knowledge.

Secondary source documents. In addition to the primary source documents, there were three secondary sources of data provided by the 48 MSPs. These sources included the following: (a) four distinct surveys submitted to the MSP Management Information System (MIS) by the MSPs; (b) written annual reports submitted every year to the NSF by the MSPs; and (c) written evaluation reports submitted to the NSF by the MSPs. These data were in numerical and narrative formats.

Data gathered on the four distinct surveys were compiled in the Compendium of MSP MIS Data for Comprehensive, Targeted, and Institute Projects (Hershey-Arista et al., 2007). The MSP MIS data compendium is a summary and synthesis document based on the results obtained from the four surveys completed by the 48 MSPs during each year of their projects. The compendium includes summaries from four rounds of survey administration that took place over four years. The MSP MIS does not include cumulative information on teachers, but rather the MSPs report teacher information for the given year only. Information in the compendium summarized numerical, multiple-choice, and open-ended answers in a tabular format.

Each year, MSPs are required to submit to the NSF written annual reports and written evaluation reports. In the present analysis, we examined 107 annual reports and 102 evaluation reports. The annual reports included the following: 19 year- 6 reports, 30 year- 5 reports, 34 year- 4 reports, 21 year- 3 reports, and 3 year- 2 reports. The evaluation reports included the following: 13 year- 6 reports, 28 year-5 reports, 36 year- 4 reports, 21 year- 3 reports, and 4 year-2 reports. Due to the length of these reports (ranging from 100 to over 700 pages) and due to the specific nature of the present inquiry on growth in teachers' content knowledge, this analysis employed a search technique using key terms on Adobe Acrobat Reader to identify information related to teacher content knowledge growth. One lead evaluator of the MSP-PE read all of the most recent reports from each of the 48 MSPs in their entirety. The analysis of the reports used a method of crosschecking information to maximize the incidence of locating data pertinent to the analysis. 
Table 1

Number of K-12 Teachers and Amount of Professional Development Received Between 2002 and 2006 in the NSF MSP Program

\begin{tabular}{|c|c|c|c|c|c|c|c|c|}
\hline \multirow{2}{*}{$\begin{array}{l}\text { Amount of MSP PD } \\
\text { All K-12 teachers }\end{array}$} & \multicolumn{2}{|c|}{$\begin{array}{c}2002-2003 \\
(n=167 \text { districts })\end{array}$} & \multicolumn{2}{|c|}{$\begin{array}{c}2003-2004 \\
(n=397 \text { districts })\end{array}$} & \multicolumn{2}{|c|}{$\begin{array}{c}2004-2005 \\
(n=445 \text { districts })\end{array}$} & \multicolumn{2}{|c|}{$\begin{array}{c}2005-2006 \\
(n=586 \text { districts })\end{array}$} \\
\hline & 3,115 & $(100 \%)$ & 17,237 & $(100 \%)$ & 29,082 & $(100 \%)$ & 33,103 & $(100 \%)$ \\
\hline $1-80$ hours & 2,662 & $(85.5)$ & 15,669 & $(90.9)$ & 27,231 & $(93.6)$ & 30,654 & $(92.6)$ \\
\hline $81-160$ hours & 390 & $(12.5)$ & 1,153 & $(6.7)$ & 1,694 & $(5.8)$ & 1,397 & $(4.2)$ \\
\hline 161 or more hours & 63 & (2) & 415 & $(2.4)$ & 428 & $(1.5)$ & 470 & (1.4) \\
\hline
\end{tabular}

Note. Data in this table were extracted from table A.4.5 (Hershey-Arista et al., 2007).

\section{Data Analysis and Synthesis}

Researchers analyzed data using qualitative methods for a document analysis of primary and secondary sources (Miles \& Huberman, 1994; Patton, 1990). We employed a content analysis approach to construct a categorical system (Fraenkel \& Wallen, 1993) for organizing the data into two major themes: (1) processes for measuring growth in teachers' mathematics and science content knowledge and (2) pathways used to promote growth in teachers' mathematics and science content knowledge. Based on the results of prior research on the instruments used by the NSF MSPs (Moyer-Packenham et al., 2008), it was anticipated that MSPs would have pre- and posttesting data from teachers' participation in contentfocused courses and workshops, as well as other methods for documenting growth.

As a framework for identifying pathways used to promote growth in teachers' content knowledge, the team examined research on professional development variables that improve teachers' practice and student learning (Darling-Hammond et al., 2009) and used a coding process based on this research identifying effective features of professional development for teachers of mathematics and science (Garet, Porter, Desimone, Birman, \& Yoon, 2001). The inquiry and analysis focused on core features (i.e., content knowledge, active learning, and coherence with other activities) within the structural features (i.e., form of the activity, collective participation, and duration) designed by the MSPs. These core and structural features guided the inquiry and supported the development of a framework.

\section{Results}

The results are organized in two major sections: (1) processes for measuring growth in mathematics and science teachers' content knowledge and (2) pathways used to promote growth in teacher content knowledge. A 136 framework is introduced to demonstrate the interrelationships among processes and pathways as a critical mediating factor in the evidence on growth in teachers' content knowledge.

\section{Scope of Involvement}

The NSF MSPs provided a variety of services to university and school system partners as part of their comprehensive activities. Table 1 provides a summary of the scope of the involvement of K-12 teachers in all types of professional development provided by the MSPs. As would be expected, the numbers of teacher participants receiving professional development services increased each year.

Over this four-year period (2002-2006), a total of 82,537 K-12 teachers received MSP-provided professional development (including professional development [PD] that focused specifically on mathematics and science content and PD that did not). This number represents a close approximation to the number of K-12 mathematics and science teachers who would have received MSPprovided professional development services during the period from which pre- and post-testing data were also gathered. The majority of teacher participants were engaged in 1-80 hours of professional development. Professional development that specifically focused on mathematics and science content knowledge is a subset of this group of 82,537 K-12 teachers.

\section{Processes for Measuring Growth in Mathematics and Science Teachers' Content Knowledge}

The most common process for measuring growth in mathematics and science teachers' content knowledge among the MSPs was pre- and post-testing. Table 2 summarizes descriptive data on pre- and post-testing of 12,952 K-12 teachers. The table reports data from the 30 (of 48) MSPs that provided pre-post data on growth in teachers' content knowledge. Of the MSPs, 22 submitted pre- and post-testing data for mathematics and 13 submitted pre- 
Growth in Teacher Content Knowledge

Table 2

Teachers' Mathematics and Science Content Knowledge Gains Assessed Using Pre- and Post-Test ${ }^{1}$

\begin{tabular}{llccrr}
\hline $\begin{array}{l}\text { Type of } \\
\text { Content Gain }\end{array}$ & \multicolumn{1}{c}{$\begin{array}{c}\text { Content Topics } \\
\text { Assessed }\end{array}$} & $\begin{array}{c}N \\
\text { Participants }\end{array}$ & $\begin{array}{c}\text { No } \\
\text { Gain }\end{array}$ & $\begin{array}{c}\text { Gain, Not } \\
\text { Significant }\end{array}$ & $\begin{array}{c}\text { Gain, } \\
\text { Significant }^{2}\end{array}$ \\
\hline Math Content $^{3}$ & & 10,331 & $620(6 \%)$ & $3,232(31 \%)$ & $6,479(63 \%)$ \\
& Data/Graph/Stat & 3,025 & $0(0 \%)$ & $69(2 \%)$ & $2,956(98 \%)$ \\
& Algebra & 1,867 & $166(9 \%)$ & $1,212(65 \%)$ & $489(26 \%)$ \\
& Geometry & 1,502 & $0(0 \%)$ & $964(64 \%)$ & $538(36 \%)$ \\
& Number Operations & 726 & $157(22 \%)$ & $322(44 \%)$ & $247(34 \%)$ \\
& Fraction/Proportion & 201 & $81(40 \%)$ & $35(18 \%)$ & $85(42 \%)$ \\
Science Content ${ }^{4}$ & Nonspecific & 3,010 & $216(7 \%)$ & $630(21 \%)$ & $2,164(72 \%)$ \\
& & 2,621 & $0(0 \%)$ & $589(22 \%)$ & $2,032(78 \%)$ \\
& Chemistry & 731 & $0(0 \%)$ & $67(9 \%)$ & $664(91 \%)$ \\
& Earth Science & 396 & $0(0 \%)$ & $124(31 \%)$ & $272(69 \%)$ \\
& Biology & 387 & $0(0 \%)$ & $51(13 \%)$ & $336(87 \%)$ \\
& Physics/Physical Science & 348 & $0(0 \%)$ & $71(20 \%)$ & $277(80 \%)$ \\
& Nonspecific & 759 & $0(0 \%)$ & $276(36 \%)$ & $483(64 \%)$
\end{tabular}

Note. ${ }^{1}$ Data represent 30 MSPs; 22 MSPs submitted pre-post data on teachers' mathematics content knowledge growth; 13 MSPs submitted pre-post data on teachers' science content knowledge growth; and five MSPs submitted pre-post data on both teachers' mathematics and science content knowledge growth. ${ }^{2}$ Significant at the $p<.05, .01$, or .001 levels. ${ }^{3} N=149$ (pre-post reports). ${ }^{4} N=69$ (pre-post reports).

and post-testing data for science, with five MSPs submitting both mathematics and science data. There were 218 pre- and post-test reports, with 149 reports for mathematics and 69 reports for science.

Table 2 is organized in three categories based on the information provided by the MSPs and includes the following: participants with no gain on pre- and post-testing of mathematics or science content knowledge, participants with gains that were not statistically significant, and participants with statistically significant gains in content knowledge. Among the reports, pre- and post-testing information in mathematics was reported for 10,331 participants, with 2-2,741 participants per report and a median of 20 participants per report. The results overall indicate that $6 \%$ of participants showed no gains, $31 \%$ showed gains that were not significant, and $63 \%$ showed significant gains in mathematics content knowledge. The table further highlights mathematics and science content areas that were most commonly identified by the MSPs. The most common focus of pre- and post-testing in mathematics was on data, graphing, and statistics topics, with
$98 \%$ of participants reporting statistically significant gains in content knowledge.

The pre- and post-testing information for science included data for 2,621 participants, with 6-438 participants per report and a median of 21 participants per report. The results for science indicate that $0 \%$ of participants showed no gains, $22 \%$ showed gains that were not significant, and $78 \%$ showed significant gains in science content knowledge. Ninety-one percent of teachers pre- and posttested in chemistry topics showed statistically significant gains in content knowledge.

Table 3 shows the relationship of pre- and post-test gains for teachers in the NSF MSP and the ED-MSP Programs. It is important to note that data from the NSF MSPs represent 30 of 48 (63\%) partnerships in the program, while data from the ED-MSPs represent 128 of 436 projects (29\% of the ED-MSP portfolio). The NSF MSPs include data for K-12 teachers of mathematics and science, while the ED-MSPs report data for only K-5 teachers. The NSF MSP pre- and post-test gains are reported for K-12 teachers as a group because a large 
Table 3

The Relationship Between Pre- and Post-Test Results for the NSF MSP and ED-MSP Programs

\begin{tabular}{lccc}
\hline Type of & Number of & Number of & Percentage of \\
Content Gains & Teachers & Teachers With & Teachers With \\
& Assessed & Significant Gains & Significant Gains \\
\hline
\end{tabular}

Mathematics Content Knowledge

$\begin{array}{lrrr}\text { NSF MSP (K-12) } & 10,331 & 6,479 & 63 \% \\ \text { ED-MSP (K-5) } & 4,937 & 3,158 & 64 \%\end{array}$

Science Content Knowledge

$\begin{array}{lccc}\text { NSF MSP (K-12) } & 2,621 & 2,032 & 78 \% \\ \text { ED-MSP (K-5) } & 1,364 & 1,128 & 83 \%\end{array}$

Note. ED-MSP data based on Exhibit 18 (U.S. Department of Education, 2008).

Table 4

The Relationship Between the Use of the LMT Instrument for Pre-and Post-Testing of Teachers and All Pre-and Post-Testing of Teachers in Mathematics

\begin{tabular}{|c|c|c|c|c|}
\hline Pre- and Post-Testing Instruments & $N$ Participants & No Gain & $\begin{array}{l}\text { Gain, Not } \\
\text { Significant }\end{array}$ & $\begin{array}{c}\text { Gain, } \\
\text { Significant }^{2}\end{array}$ \\
\hline All Instruments Assessing Math Content & 10,331 & $620(6 \%)$ & $3,232(31 \%)$ & $6,479(63 \%)$ \\
\hline $\mathrm{LMT}^{1}$ Instrument (31\% of participants) & 3,220 & $601(19 \%)$ & $1,859(57 \%)$ & $760(24 \%)$ \\
\hline Other Instruments (69\% of participants) & 7,111 & $19(.3 \%)$ & $1,373(19 \%)$ & $5,719(81 \%)$ \\
\hline
\end{tabular}

Note. ${ }^{1}$ LMT $=$ Learning Mathematics for Teaching. ${ }^{2}$ Significant at the $p<.05, .01$, or .001 levels.

portion of the data reported ( $80 \%$ for science; $77 \%$ for mathematics) did not identify a specific grade level.

There are some similarities in the results for each of the MSP Programs. Both data sets represent approximately $15-16 \%$ of the teachers served by the program at the time of reporting (NSF MSP: 12,952 of 82,537 teachers served, 16\%; ED-MSP: 5,637 of 37,355 teachers served, $15 \%$ ). This indicates that $15-16 \%$ of teachers in both programs participated in pre- and post-testing of content knowledge. In both programs, there appear to be more teachers focused on developing content knowledge in mathematics than in science. Finally, both sets of results indicate a higher percentage of teachers with significant content gains in science than in mathematics.

The most frequently used instrument to measure teachers' content knowledge in the NSF MSP Program was for mathematics and measured MKT (Ball, 1991; Hill \& Ball, 2004; Hill et al., 2005). The two examples that follow are typical descriptions on the use of the LMT instrument from the MSPs' reports:

- To gauge the impact of the Geometry and Measurement course on teachers' content knowledge, a multiple-choice content assessment based on items developed at the University of Michigan (Hill, Schilling, \& Ball, 2004) was administered to the participants prior to and at the completion of the institute. (p. 40)

- The goal of these instruments was to further research into the specific knowledge needed for the teaching of mathematics. The elementary and middle school versions were forms developed by the Study for Instructional Improvement (Rowan, Schilling, Ball, \& Miller, 2001). The high school version was a pilot of items developed to extend the work of SII into high school. (p. 8)

Table 4 summarizes pre- and post-testing of teachers using the LMT instrument and pre- and post-testing of teachers using all other instruments used to assess teachers' mathematical content knowledge. The 3,220 teachers assessed using the LMT instrument are a subset of all of the teachers assessed on mathematics content $(10,331)$ and represent approximately $31 \%$ of the pre- and post-tests reported for mathematics. Almost all of the "no gains" 
reported for mathematics were reported with the use of LMT instrument items (601 of 620 teachers tested). When comparing gains using the LMT instrument with other instruments used to assess content knowledge, 24\% of teachers showed significant gains on pre- and post-tests when the LMT instrument was used; comparatively, $81 \%$ of teachers showed significant gains on pre- and post-tests when other instruments were used. These results show a substantial difference between teacher outcomes when different instruments are used to assess mathematics content knowledge.

Another less common method of documenting growth in teacher content knowledge was observations of teaching. While numerous MSPs reported teacher observations, only eight MSPs provided 16 pre-post observation reports that included scoring of teachers' content knowledge growth (eight for mathematics; eight for science). The most common instrument for conducting teacher observations was the Reformed Teaching Observation Protocol (RTOP), used in nine of 16 reports (Piburn, Sawada, Falconer, Turley, Benford, \& Bloom, 2000). An additional method used by the MSPs to provide evidence of growth in teacher content knowledge in mathematics and science was the documentation of course taking, participation in certification programs, or the acquisition of a mathematics or science degree.

\section{Pathways Used to Promote Growth in Teacher Content Knowledge: Explicit and Embedded}

The results showing growth in teachers' content knowledge revealed that there were two distinct pathways for promoting growth: pathways where the goal of growth in teacher content knowledge was explicit and pathways where the goal was embedded. We highlight this distinction with an organizational framework for these two categories, with the properties and characteristics of each category, and related examples. The framework in Table 5 shows two major pathways promoting growth in teacher content knowledge - content-explicit pathways and content-embedded pathways - with their corresponding processes for measuring growth in teacher content knowledge. This framework illuminates the interrelationships among the pathways and processes as they mediate the content knowledge growth.

Content-explicit pathways. The content-explicit pathways used by the MSPs were activities where growth in teacher content knowledge was a focal or primary goal of the activity. These teacher activities were designed to teach mathematics and science content with an explicit purpose of learning the content. The two most common explicit pathways used are the following: (1) mathematics and science content workshops and (2) university activity. The content workshops included one-day workshops, weeklong seminars, weekly or monthly content-focused meetings, mathematics/science camps and institutes, workshops where teachers learned to use mathematics/science kits, and program training (e.g., Saxon curriculum training). Workshops varied on continuums of length, focus, location, activity level, and decision making. In terms of length, some workshops were held for a few hours after school while others lasted a year or more. There were workshops with a narrow focus, such as Pebbles, while others featured broad topics such as algebra or geometry. Some workshops focused on the integration of mathematics and science. A report submitted by one MSP (No. 39) noted:

Paula is a [project] math teacher who has found that using the context of the physics of motion from the [project] course has helped her understand better and explain better the math that she had been teaching. She says, ... with the physics background I gained from this course I am planning to incorporate "labs" into my math classes. (p. 106)

In terms of location, some workshops were held at a school with only the school faculty involved; others held conferences or online courses, which included teachers from across a state or region; and one project involved their teachers in a dinosaur dig. With regard to activity level, there were workshops and training where participants simply listened to a presentation; other workshops included hands-on experiences with kits that teachers would later use in their classrooms. Workshops varied in the degree of teacher decision making in their selection and structure. In some MSPs, a steering committee or leadership group decided the content and design of the professional development, while others allowed teachers to identify their needs and matched those needs with the professional development design. These varying factors influenced the structure of the training and the depth of content knowledge teachers gained.

The university activity designed by MSPs included the completion of mathematics and science content courses, master's degrees in mathematics and science, and endorsements/certifications. Some teachers attended courses in already established programs, while other universities designed new programs and courses for teachers. One MSP (No. 10) reported:

Once the new (textbook) adoption was announced, the [project] developed two university courses, one for 
Table 5

Framework of Pathways and Processes for Growth in Teacher Content Knowledge

PATHWAYS

Promoting Growth in Teacher Content Knowledge

\section{PROCESSES}

Measuring Growth in Teacher Content Knowledge

\section{CONTENT EXPLICIT}

Mathematics and science content is focal to the activity

Mathematics and Science Content Workshop

One/two days

Week-long seminars

Weekly/monthly meetings

Math and science camps

Math and science institutes

Workshops with kits

Program training

University Activity

Completion of university content courses

Master's degrees

Math or science endorsement/certification
Pre-post content knowledge tests

Beliefs about content knowledge (surveys)

Use of PD concepts in classroom (surveys)

Monthly teacher checklist (surveys)

Professional development practice (surveys)

Observations (portion on content knowledge)

Interviews (portion on content knowledge)

Course grades, Grade Point Average

Pre-post content knowledge tests

Degree/endorsement/certification completion

Course projects/products

\section{CONTENT EMBEDDED}

Mathematics and science content is embedded in the activity

Mathematics and Science Focus Groups

Lesson study groups

Textbook adoption groups

Video study groups

Learning communities

Assessment groups

Consulting with experts

Teacher Leadership

Leaders' focus groups

School consultant/content coach/specialist

PD designer/presenter

Participate in the development of courses

Mathematics and Science Teaching

Develop lesson plans for own class

Read mathematics and science journals

Watch mathematics and science videos

Conduct a science experiment

Observe someone else teaching

Solve your own mathematical problem

Gather content information (Internet, nature shows, newspapers, readings)

\section{Embedded in the Work of a Group}

Attendance (duration of attendance)

Duration of interaction

Group product (group lesson, adoption of textbook, group content discussion, group grading of district-level tests while discussing the content)

School culture changes (survey)

\section{Embedded in the Work of a Leader}
Attendance (duration of attendance)
Duration of interaction
Develop and deliver a content course (feedback)
Design PD for other teachers (feedback)
Lead a group discussion on content (feedback)

\section{Embedded in the Work of a Teacher}

\author{
Lesson plans \\ Reflections \\ Individual products
}


each program, to provide professional development in the new curriculum. Each course is designed to address the development of the mathematical ideas in the curriculum. (p. 23)

When the MSPs promoted teachers' content knowledge growth through an explicit pathway (i.e., workshops or university activity), the processes for measuring knowledge growth were often tests with reliability and validity, used across multiple MSPs, and widely known and accepted by the research community (e.g., LMT instrument and RTOP instrument). Some of the measures used by MSPs were pre- and post-tests of content knowledge, course grades, grade point averages, degrees or endorsements, surveys of teachers' content knowledge, surveys of teacher practice, classroom observations of the implementation of content, and teacher interviews about changes in content. The following example describes a method for assessing teachers' content knowledge reported by one MSP (No. 41):

The instructor observed the teachers while they solved problems during their content class. A behavioral checklist was used to document teacher growth during problem solving ... (p. 41)

However, as the following example from another MSP (No. 40) indicates, instructors in some courses struggled to identify reliable methods for documenting growth in teacher content knowledge.

As course instructors developed assessments, a number of questions were raised about the teacher content inventory as a tool. Instructors felt that they were getting limited feedback about teacher science knowledge, skills, the extent of misconceptions, and worldview. Instructors had difficulty developing tests that they felt were representative of the content they hoped teachers would learn and issues of validity and reliability made the tests difficult to analyze. (p. 23)

Content-embedded pathways. The content-embedded pathways used by the MSPs were activities where growth in teacher content knowledge was embedded in the work of the activity, and learning content was one of several anticipated outcomes of the activity. Most of the contentembedded teacher activities were designed as group collaboration, leadership development, or individual study, where learning mathematics and science content was not the only purpose of the activity. The content-embedded pathway activities were embedded in the work of a group, embedded in the work of a leader, or embedded in the work of a teacher.

Content knowledge development that was embedded in the work of a group included STEM study groups (27 of the $48 \mathrm{MSPs}$ ), mathematics/science learning communities (25 MSPs), focus groups (24 MSPs), peer coaching groups (20 MSPs), textbook adoption groups (14 MSPs), lesson study groups (8 MSPs), teacher discussion groups (6 MSPs), video study groups (5 MSPs), and assessment groups (5 MSPs) (portions from table A.4.1, HersheyAriste et al., 2007). Teachers developed content knowledge while working in groups in several different ways. One way was to develop knowledge by exposure to new concepts through the group study of a book, research material, or educational media that was led by a content expert, as reported by the following MSP (No. 30).

Teachers emphasized the importance and value of having a mathematician lead the group. Several teachers commented that it wasn't a specific area or topics studied within the group that was most valuable for their work, but rather [the project's] integrated approach to the understanding and teaching of mathematics. This approach was modeled by the mathematician. (p. 17)

Another way to develop content knowledge was to learn content collaboratively when engaged in a video observation analysis, case studies, or assessment analysis, as reported by MSP No. 42.

For Video Club... The team selects a five-seven minute segment from the tape. The participants work through the relevant part of the mathematical activity that will be seen in the video clip: the facilitator leads a discussion about the problem... The goal of this discussion is to help teachers deepen their understanding of mathematical content... (p. 42)

University faculty were often engaged with teacher groups through email consulting, content focus groups, and classroom observations. The following examples from MSP reports (Nos. 14 and 21) show the work of university faculty in collaboration with classroom teachers:

- This professor and I continued our combined efforts by developing several lessons for middle school teachers using technology such as the CBR, TI-83 graphing calculator and the TI Voyage 
calculator. We co-taught several times in middle school classrooms. (p. 12)

- A total of 7 content experts worked with participants through the [project] site-3 life scientists, 1 physicist, 1 organic chemist, 1 earth scientist, and 1 math educator. (p. 78)

The previous examples demonstrate how the development of mathematics and science content knowledge was embedded in a variety of group activities within the partnerships.

When teacher content knowledge development was embedded in the work of a leader, it was the direct and indirect result of a variety of leadership responsibilities. The development of teacher leaders was described by 42 of 48 MSPs, with more teacher leaders in mathematics than in science in the program. The development of content knowledge was embedded in teacher leaders' roles and responsibilities along several dimensions including the leader's time commitment, jurisdiction, professional development, and responsibilities. Leader variations and dimensions are identified by Taylor (2008) in a report on roles and responsibilities of instructional coaches. Table 6 summarizes those identified in the present analysis.

In terms of the teacher leaders' commitment to the MSP, some leaders were involved in project-specific professional development (e.g., assessment or curriculum development) and were leaders only for the duration of a specific project. Other teacher leaders were engaged in continuous development and became full-time mathematics consultants observing and coaching teachers. With regard to the leaders' jurisdiction, some were responsible for a team, a school, multiple schools, the district, or an entire region. Assignments could include a single grade level or several grade levels, with different content topics included in their responsibilities. Many leaders were participants as well as providers of professional development. For example, leaders received extra content knowledge training and had added opportunities to gain knowledge through collaboration with experts and other teacher leaders, as exemplified in the following example (MSP No. 4):

- We offered forty-eight hours of coaching training that had a twofold purpose: to deepen the coaches' content knowledge and to provide them with strategies, tools, and techniques to help math and science teachers implement rigorous curricula and high quality teaching practices in their classrooms. (p. 2)
Teacher leaders designed and delivered professional development for other teachers (29 of 48 MSPs), served as school consultants (23 MSPs), lead focus groups (19 MSPs), mentored new teachers (12 MSPs), and presented and published ( 9 MSPs). They were also involved in curriculum, parent education, evaluating teachers, research activities, and equipment administration. Embedded in all of these activities was the opportunity for growth in leaders' mathematics and science content knowledge.

It is difficult to summarize the content knowledge development in the NSF MSP program that was embedded in the work of individual teachers. This type of development often included teachers working individually in their own classrooms to (a) develop lesson plans for their own teaching; (b) read mathematics and science journals; (c) watch mathematics and science videos; (d) conduct a science experiment; (e) observe someone else teaching; (f) solve one's own mathematical problems; or (g) gather content information from nature shows, newspapers, the Internet, and personal readings, as in the following example (MSP No. 20):

Teachers documented content knowledge growth with artifacts of their learning and reflections on their learning throughout the project and within each of the major content strands ... They developed lesson plans and activities appropriate for their grade levels taught, collected samples from student work and analyzed that student work noting areas of misconceptions and action plans to address those misunderstandings. (p. 13)

Some MSPs developed resource centers that could be accessed by individual teachers (not just MSP participants) to support content knowledge development. These resources included physical and online locations where teachers could find expert help, resource materials, ideas for lesson plans, and supplemental information. Voluntary involvement in these types of self-initiated activities would have influenced teachers' content knowledge; however, it was challenging for MSPs to measure this type of content-embedded teacher knowledge growth.

Processes for measuring growth in teacher content knowledge were much less clear when it was embedded in the work of groups, leaders, or individual teachers. MSPs used many different measures including attendance records, duration of the interaction, an outcome of the group or leadership activity, teachers' written reflections, surveys, or journals, and feedback on the development and delivery of a content course for other teachers. In some cases, changes in teachers' content knowledge were a by-product or one of the several outcomes intended for the 
Growth in Teacher Content Knowledge

Table 6

Variations in the Role of a Teacher Leader

\begin{tabular}{|c|c|c|c|}
\hline \multicolumn{4}{|c|}{ Variations in the Role of a Teacher Leader } \\
\hline Commitment & Jurisdiction & Development & Responsibilities \\
\hline Duration & Magnitude & Course Work & Professional Development \\
\hline Project Only & Team & & Designing \\
\hline One Year & School & Content & Presentation \\
\hline \multirow[t]{2}{*}{ Multiple Years } & Multischool & Methods & Mentor/Consultant \\
\hline & District & Pedagogy & \\
\hline \multirow{3}{*}{$\begin{array}{l}\text { Involvement } \\
\text { Full Time Leader } \\
\text { Part Time }\end{array}$} & Region & Leadership & Parent Education \\
\hline & & Instruments & Courses \\
\hline & Level & Observation & Events \\
\hline \multirow{3}{*}{$\begin{array}{l}\text { Teacher/Part Time } \\
\text { Leader } \\
\quad \text { Full Time Teacher }\end{array}$} & Single Grade & Assessment & \\
\hline & Multigrades & & Teacher Assessment \\
\hline & & Consultation & Classroom Observation \\
\hline & Subject & Administrators & Test Administration \\
\hline & Topics & University & \\
\hline & General Area & Subject Experts & Student Activities \\
\hline & & & Science Fairs \\
\hline & & & Study Groups \\
\hline & & & Events \\
\hline & & & Curriculum Development \\
\hline & & & Lessons/Units \\
\hline & & & Assessments \\
\hline & & & Supplements \\
\hline & & & Piloting Programs \\
\hline & & & Research \\
\hline & & & Action Research \\
\hline & & & University Co-partner \\
\hline & & & Conference Presenter \\
\hline & & & Grant Writing \\
\hline & & & Equipment Distribution and \\
\hline & & & Maintenance \\
\hline & & & Committee Member \\
\hline & & & Steering \\
\hline & & & Textbook Adoption \\
\hline & & & Media Representation \\
\hline
\end{tabular}


activity. Teacher leaders were expected to have strong influences on the content knowledge of other teachers. As a result, some projects demonstrated evidence of the leaders' growth in content knowledge through pre-post content testing, or observations and survey questions asking teachers, teacher leaders, and administrators to evaluate the teacher leaders' content knowledge. As these varied methods demonstrate, it was challenging to measure growth in content knowledge when the development of knowledge was embedded in activities.

\section{Discussion}

The purpose of this study was to determine how partnerships in the NSF MSP Program developed processes for measuring growth in teacher content knowledge and examine the extent to which the pathways used to promote growth were related to those processes. The results show that processes for measuring growth in teacher content knowledge are intertwined with the pathways used to promote content knowledge growth.

The findings on processes for measuring growth in teachers' mathematics and science content knowledge indicate that pre- and post-testing of teachers continues to be the most common method for measuring teacher growth, similar to previous findings by Moyer-Packenham et al. (2008). Also corroborating previous findings (Moyer-Packenham et al., 2008), the LMT instrument continues to be the most frequently used of the identified instruments in the program (31\% of the mathematics instruments). Interestingly, when the $L M T$ instrument was used to assess growth in teachers' mathematics knowledge, $24 \%$ of teachers showed significant gains, compared with $81 \%$ showing significant gains when other pre-post measures were used. A variety of published studies show that research on the psychometric properties of the LMT instrument has been quite extensive (Hill, 2007; Hill \& Ball, 2004; Hill et al., 2005, 2007; Schilling, 2007; Schilling, Blunk, \& Hill, 2007). Findings from pre-post measures that have not undergone this type of psychometric scrutiny must be interpreted with caution.

When comparing the results of pre- and post-testing of teachers between the NSF MSPs and the ED-MSPs, similarities emerged. The U.S. Department of Education's (2008) report showed that $15 \%$ of teachers served by the ED-MSP Program were participants in pre- and posttesting of mathematics or science content knowledge. Similarly, $16 \%$ of teachers in the NSF MSP Program were participants in pre- and post-testing. There are large portions of teacher participants in both programs whose growth in mathematics and science content knowledge is being measured using other methods or is not being measured at all. This raises the following question: Do the NSF and the Department of Education need to request the same specific processes for measuring growth from all of their participating partnerships?

The results showing pre- and post-test gains for K-12 teachers in the present study indicated that $78 \%$ of teachers tested in science demonstrated statistically significant gains in content knowledge, while $63 \%$ of teachers tested in mathematics showed significant gains. These results are similar to the ED-MSP's findings on the pattern of significant content gains for teachers. One explanation for this pattern in both programs is the inherent nature of the two disciplines. Mathematics may be more content connected, where new content learned is more dependent on the learning of previous content, whereas some science topics may be discrete with less dependence on the learning of other science topics. Additionally, the discreet nature of science topics may make it easier to develop assessments that are more focused on the topics taught in a science course, whereas mathematics tests may be more comprehensive and learners may need to rely on prerequisite learning that was outside of the scope of the project.

The results show two predominant pathways used by the NSF MSPs to promote growth in teacher content knowledge: content explicit and content embedded. The contentexplicit pathways appear to be most aligned with traditional methods of teacher development and include workshops and university activity. The content-embedded pathways appear to be aligned with more reform-oriented methods and include content development that is embedded in the work of groups, leaders, and individual teachers.

In a recent report on teacher professional development in the United States, Darling-Hammond et al. wrote, "Overall, the kind of high-intensity, job-embedded collaborative learning that is most effective is not a common feature of professional development across most states, districts, and schools in the United States" (DarlingHammond et al., 2009, p. 4). In the present study, it appears that the "high-intensity, job-embedded collaborative learning" to which Darling-Hammond et al. refer is becoming more and more prominent in the work of the NSF MSPs. A previous analysis of the NSF MSPs indicated that activities such as study groups, mentoring/ coaching, learning communities, and lesson study were present in less than $2.5 \%$ of all professional development activities (Moyer-Packenham et al., 2010). The current findings show that these activities are more widespread throughout the NSF MSP Program. 
The shift in teacher professional development activities from content-explicit to content-embedded pathways presents a unique dilemma for the MSPs; namely, it is a greater challenge to measure growth in teacher content knowledge when the content knowledge is embedded in teachers' work. On one hand, this type of job-embedded learning exemplifies what research shows to be more effective for teaching practice and student learning (Darling-Hammond et al., 2009; Garet et al., 2001); yet, on the other hand, processes for measuring "job-embedded collaborative learning" pose a dilemma for researchers and evaluators in funded programs such as the NSF MSP and ED-MSP. To highlight this specific challenge, we propose that readers consider the following: How would you measure growth in teachers' mathematics and science content knowledge in each of the following contentembedded activities:

- Teachers examine student work and, as a result, discuss mathematics and science content;

- Teachers work on curriculum adoption, selection, or development, where learning additional content is a by-product of their work;

- Teachers take on a leadership role as an instructor or content coach, and in teaching others, they learn mathematics and science content themselves; and

- Teachers participate in a Lesson Study Group or a Professional Learning Community where content is part of the group interactions and discussions.

As these examples demonstrate, clear measures for this type of teacher knowledge growth require a new approach to evaluation design. Learning mathematics and science content that is embedded in one's work may make that learning more meaningful and closely tied to teachers' classroom practices; however, this type of content-embedded learning is also more of a challenge for project directors and evaluators in programs such as the NSF MSP to document and measure. When teachers' content knowledge development is embedded in their work, it is personal, situational, individual, and context specific. When a mathematics and science group chooses to take on a particular activity in which content is a part of the activity, the group may not identify the content they will learn until they are immersed in the activity and determine what it is they need to know to accomplish their goal. This inability to identify exactly what content will be learned makes measuring growth in teacher content knowledge extremely challenging. The results of this inquiry demonstrate that there are measures that provide evidence that teachers in the NSF MSP Program have made significant gains in their content knowledge in a variety of mathematics and science topic areas. However, as projects increase the use of contentembedded pathways for teachers' content development, evaluation of that development poses a unique challenge which may result in large numbers of teachers for whom growth in mathematics and science content knowledge is underreported, complicated to document, or not measured at all.

\section{References}

Ball, D. (1991). Research on teaching mathematics: Making subject matter knowledge part of the equation. In J. Brophy (Ed.), Advances in research on teaching (Vol. 2, pp. 1-41). Greenwich: JAI Press.

Bolyard, J. J., \& Moyer-Packenham, P. S. (2008). A review of the literature on mathematics and science teacher quality. Peabody Journal of Education, 83(4), 509-535.

Conference Board of the Mathematical Sciences. (2001). The mathematical education of teachers - Issues on mathematics education (Vol. 11). Providence, RI: American Mathematical Society.

Council of Scientific Society Presidents. (2004). The need for well-qualified science and math teachers. Retrieved August 5, 2009, from http://cssp.us/ pdf/CSSP.Issue.Well.Qualified.Teachers.pdf

Darling-Hammond, L. (2000). Teacher quality and student achievement: A review of state policy evidence. Educational Policy Analysis Archives, 8, $1-50$.

Darling-Hammond, L., Wei, R. C., Andree, A., Richardson, N., \& Orphanos, S. (2009). Professional learning in the learning profession: A status report on teacher development in the United States and abroad. National Staff Development Council.

Darling-Hammond, L., \& Youngs, P. (2002). Defining "highly qualified teachers:" What does "scientifically-based research" actually tell us? Educational Researcher, 31(9), 13-25.

Fraenkel, J. R., \& Wallen, N. E. (1993). How to design and evaluate research in education (2nd ed.). New York: McGraw-Hill.

Garet, M. S., Porter, A. C., Desimone, L., Birman, B. F., \& Yoon, K. S. (2001). What makes professional development effective? Results form a national sample of teachers. American Educational Research Journal, 38, 915 945.

Goldhaber, D. D., \& Brewer, D. J. (1997). Why don't schools and teachers seem to matter? Assessing the impact of unobservables on educational productivity. The Journal of Human Resources, 32, 505-523.

Hershey-Arista, M., Miyaoka, A., Silverstein, G., \& Frechtling, J. (2007). Compendium of MSP MIS data for comprehensive, targeted, and institute projects: 2002-03, 2003-04, 2004-05, 2005-06 School years. Rockville, MD: Westat.

Hill, H. C. (2007). Mathematical knowledge of middle school teachers: Implications for the No Child Left Behind Policy initiative. Educational Evaluation and Policy Analysis, 29, 95-114.

Hill, H. C., \& Ball, D. L. (2004). Learning mathematics for teaching: Results from California's mathematics professional development institutes. Journal for Research in Mathematics Education, 35(5), 330-351.

Hill, H. C., Dean, C., \& Goffney, I. M. (2007). Assessing elemental and structural validity: Data from teachers, non-teachers, and mathematicians. Measurement: Interdisciplinary Research \& Perspective, 5(2), $81-92$.

Hill, H. C., Rowan, B., \& Ball, D. L. (2005). Effects of teachers' mathematical knowledge for teaching on student achievement. American Educational Research Journal, 42(2), 371-406.

Hill, H. C., Schilling, S. G., \& Ball, D. L. (2004). Developing measures of teachers' mathematics knowledge for teaching. The Elementary School Journal, 105, 11-30. 
Miles, M. B., \& Huberman, A. M. (1994). Qualitative data analysis (2nd ed.). Thousand Oaks, CA: Sage Publications.

Moyer-Packenham, P. S., Bolyard, J. J., Kitsantas, A., \& Oh, H. (2008). The assessment of mathematics and science teacher quality. Peabody Journal of Education, 83(4), 562-591.

Moyer-Packenham, P. S., Bolyard, J. J., Oh, H., \& Cerar, N. I. (2010) Common features of professional development activities for mathematics and science teachers. Professional Development in Education, 1-19. doi $=10.1080 / 19415257.2010 .531597$

National Center for Education Statistics. (2005). Characteristics of public school teachers' professional development activities: 1999-2000. Issue Brief, August 2005. U.S. Department of Education.

National Council of Teachers of Mathematics. (2005). Highly qualified teachers. Retrieved August 5, 2009, from http://www.nctm.org/about/ content. aspx?id=6364

National Science Foundation. (2005). Memorandum: Committee of visitors report for the math and science partnership program. Retrieved August 5, 2009, from http://www.nsf.gov/od/oia/activities/cov/ehr/2005/MSPcov.pdf

National Science Foundation. (2007, January 7). NSF's math and science partnerships demonstrate continued increases in student proficiency. Press Release 07-005, retrieved August 5, 2009, from http://www.nsf.gov/news/ news_summ.jsp?cntn_id=108299

National Science Teachers Association. (2004). Science teacher preparation. Retrieved August 5, 2009, from http://www.nsta.org/about/positions/ preparation.aspx

Patton, M. Q. (1990). Qualitative evaluation and research methods (2nd ed.). Thousand Oaks, CA: Sage Publications.

Piburn, M., Sawada, D., Falconer, K., Turley, J., Benford, R., Bloom, I. (2000). Reformed Teaching Observation Protocol (RTOP). ACEPT IN-003. The RTOP rubric form, training manual and reference manual containing statistical analyses, are all available from http://PhysicsEd.BuffaloState.Edu/ AZTEC/rtop/RTOP_full/PDF/

Rice, J. K. (2003). Teacher quality: Understanding the effectiveness of teacher attributes. Washington, DC: Economic Policy Institute.

Rowan, B., Schilling, S., Ball, D., \& Miller, R. (2001). Measuring teachers' pedagogical content knowledge in surveys: An exploratory study. Consortium for Policy Research in Education, Study of Instructional Improvement, Research Note S-2. Ann Arbor, MI: University of Michigan.

Schilling, S. G. (2007). The role of psychometric modeling in test validation: An application of multidimensional item response theory. Measurement: Interdisciplinary Research \& Perspective, 5(2), 93-106.

Schilling, S. G., Blunk, M., \& Hill, H. C. (2007). Test validation and the MKT measures: Generalizations and conclusions. Measurement: Interdisciplinary Research \& Perspective, 5(2), 118-128.

Taylor, J. E. (2008). Instructional coaching: The state of the art. In M. M. Mangin \& S. R. Stoelinga (Eds.), Effective teacher leadership: Using research to inform and reform (pp. 10-35). New York: Teachers College Press.

U.S. Department of Education. (2008). Mathematics and science partnerships: Summary of the fiscal year 2005 annual reports. (Contract ED04CO0015/0003). Washington, DC: U.S. Department of Education.

Wilson, S. M., Floden, R., \& Ferrini-Mundy, J. (2001). Teacher preparation research: Current knowledge, gaps, and recommendations. A research report prepared for the U.S. Department of Education. Seattle: Center for the Study of Teaching and Policy, University of Washington.

\section{Authors' Notes}

${ }^{1}$ This article is one of a series of studies for the MSP-PE conducted for the NSF MSP Program. The MSP-PE is conducted under Contract No. EHR-0456995. Since 2007,
Bernice Anderson, Ed.D., Senior Advisor for Evaluation, Directorate for Education and Human Resources, has served as the NSF Program Officer. The MSP-PE is led by COSMOS Corporation. Robert K. Yin (COSMOS) serves as Principal Investigator. Darnella Davis (COSMOS) serves as one of the three Co-Principal Investigators. Additional Co-Principal Investigators are Kenneth Wong (Brown University) and Patricia Moyer-Packenham (Utah State University). Any opinions, findings, conclusions, and recommendations expressed in this article are those of the author(s) and do not necessarily reflect the views of the NSF.

${ }^{2}$ One of the 48 partnerships ended in 2005 by mutual consent with the NSF and is not included in some of the other reports produced by the MSP-PE. 